Proc. Indian Acad. Sci. (Earth Planet. Sci.), Vol. 95, No. 2, July 1986, pp. 183-191.

(C) Printed in India.

\title{
Cosmogenic isotope and track records in meteorites and their impli- cations to cosmic ray fluxes
}

\author{
NARENDRA BHANDARI \\ Physical Research Laboratory, Navrangpura, Ahmedabad 380009, India
}

MS received 15 March 1985; revised 23 April 1986

\begin{abstract}
Study of several cosmic ray effects, such as VH track density, spallogenic ${ }^{26} \mathrm{Al}$ and ${ }^{53} \mathrm{Mn}$ activity, ${ }^{21} \mathrm{Ne}$ and ${ }^{22} \mathrm{Ne} /{ }^{21} \mathrm{Ne}$ ratio, made in the same sample or in cores taken from different meteorites can identify parameters related to the exposure history of meteorites and cosmic ray flux variations. Meteorites with single or multiple exposure can be distinguished from a track production rate $-{ }^{22} \mathrm{Ne} /{ }^{21} \mathrm{Ne}$ correlation diagram and cosmic ray flux variations over $10^{6}-10^{7}$ years can be deduced from a three-isotope correlation diagram of ${ }^{26} \mathrm{Al},{ }^{33} \mathrm{Mn}$ and ${ }^{21} \mathrm{Ne}$. Isotopic data based on chondrites with simple, one-stage exposure are consistent with the same avetage galactic cosmic ray intensity over the past 2 million years as that during the past $10^{7}$ years.
\end{abstract}

Keywords. Cosmogenic isotopes; meteorites; cosmic ray fluxes.

\section{Introduction}

The possibility that meteorites, having long term cosmic ray records in the form of isotopic products resulting from nuclear reactions and heavy nuclei ( $\mathrm{vH}$ ) tracks, can be used for monitoring cosmic ray fluxes in the past has been discussed since the early work of Arnold et al (1961). Calculations show that the rates of production of these cosmic ray effects depend significantly on the shielding depth within a meteorite (Bhattacharya et al 1980; Eberhardt et al 1966; Fleischer et al 1967). Also, the meteorites are not always exposed to cosmic rays in a fixed geometry because of multiple exposure on their parent bodies (Bhandari and Potdar 1982), fragmentation in space and space erosion. The effects of these processes have to be quantitatively assessed before the isotopic data in meteorites can be used to infer cosmic ray intensity. Because of these complications, there is considerable debate on the changes in the cosmic ray flux inferred from meteorite data. Nishiizumi et al (1980) and Müller et al (1981) have proposed that the cosmic ray intensity over the past $2 \times 10^{6}$. years was higher as compared to the average intensity before that. This is based on statistical analyses of ${ }^{26} \mathrm{Al},{ }^{53} \mathrm{Mn}$ and ${ }^{21} \mathrm{Ne}$ data after making empirical corrections for shielding depths but without considering the effects of various processes cited above. Recently Moniot et al (1983) have measured ${ }^{10} \mathrm{Be}$, reanalysed the data on several isotopes and concluded that temporal variations in cosmic ray flux have not occurred.

Here we discuss isotopic and track density data in some chondrites restricting ourselves to measurements which have been made in the same sample. Whereas the track density enables us to determine the shielding depth in the case of the same sample measurements, errors in shielding corrections become negligible since the shape of the production profiles of these isotopes are nearly identical. Further excluding meteorites 


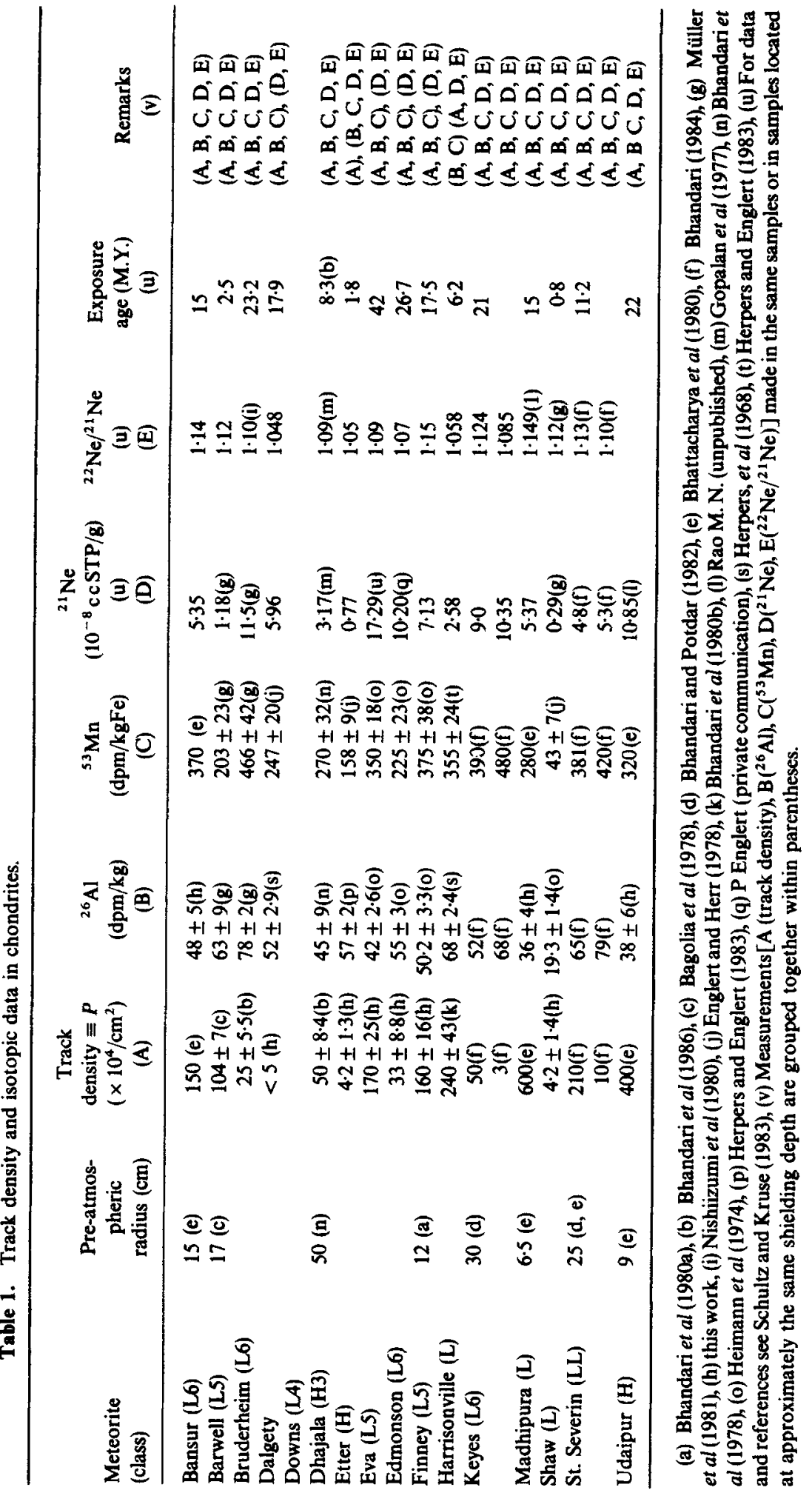


having multiple exposure and using the criteria developed earlier (Bhandari and Potdar 1982), we confine the study to chondrites with single, one-stage exposure history. A three-isotope $\left({ }^{26} \mathrm{Al}-{ }^{53} \mathrm{Mn}-{ }^{21} \mathrm{Ne}\right)$ diagram is proposed which is sensitive to cosmic ray intensity variation. The position of data points in such a diagram allows us to determine the time variation in cosmic ray flux during the past $10^{7}$ years.

\section{Experimental details and data sets}

We have selected a few meteorites which have already been extensively studied. These are listed in table 1. Track densities in many of these meteorites was not known. This was measured in minerals, olivines and pyroxenes, following standard procedures described earlier (Bhandari et al 1972). The cosmic ray track density in olivine is always smaller than in pyroxenes by a factor of two to three. A value of 2.9 has been used here to obtain equivalent density in pyroxenes for the purpose of determining shielding depths from the calculated track production profiles. Samples from Bansur, Madhipura, Udaipur and St. Severin were taken from the cores which have been studied earlier by Bhattacharya et al (1980). Samples of Keyes chondrite from different cores were kindly provided by Dr D D Bogard. Aliquots of some of the other meteorites studied here were obtained from Dr P Englert. The track density data in all these samples are listed in table 1. In case of St. Severin the track density, ${ }^{53} \mathrm{Mn},{ }^{21} \mathrm{Ne}$ and ${ }^{22} \mathrm{Ne} /{ }^{21} \mathrm{Ne}$ have been measured along several cores (Tamhane 1972; Lal et al 1969; Bhattacharya et al 1980; Englert and Herr 1980; Schultz and Signer 1976). Some ${ }^{26} \mathrm{Al}$ measurements have been made (Marti et al 1969) but a depth profile is not available. We have therefore measured ${ }^{26} \mathrm{Al}$ in some samples of core CB4 and A III on a low level gamma-gamma coincidence detector assembly using two $7.5 \mathrm{~cm} \times 7.5 \mathrm{~cm} \mathrm{NaI}(\mathrm{Tl})$ activated crystals with a plastic scintillator active anticoincidence shield. The background of the system is 1.6 $\times 10^{-3} \mathrm{cpm}$ and $\beta^{+}$counting efficiency is $2.3 \%$ for a typical sample of $40 \mathrm{~g}$. The

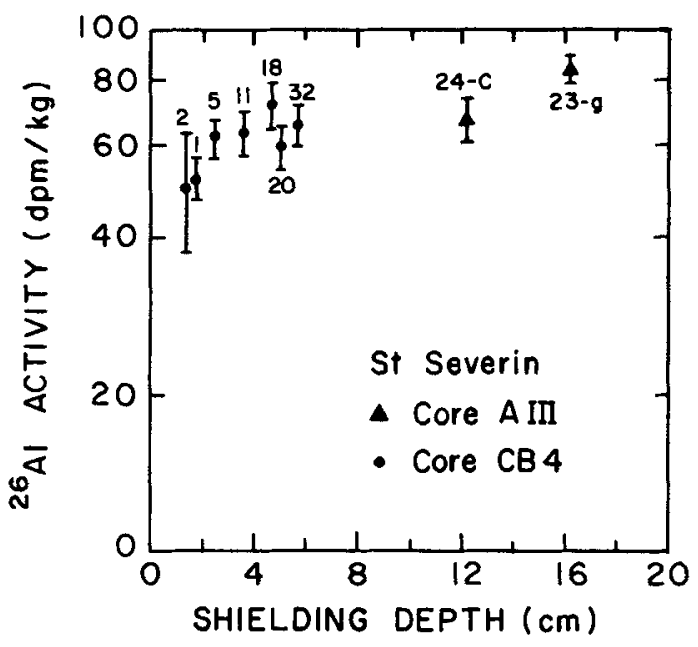

Figure 1. Preatmospheric depth profile of ${ }^{26} \mathrm{Al}$ in St. Severin core samples (Effective radius, $R_{E}=25 \mathrm{~cm}$ ). The shielding depths are calculated from the observed track density. Sample number is marked on each point. 
samples were powdered, filled in identical boxes and counted. The ${ }^{26} \mathrm{Al}$ profile is shown in figure 1 . The ${ }^{26} \mathrm{Al} /{ }^{53} \mathrm{Mn}$ ratio in five samples lie in the range 0.16 \pm 0.02 . In case of Keyes, measurements of all these isotopes are available (Cressy 1975; Englert and Herr 1978; Wright et al 1973). The ${ }^{26} \mathrm{Al} /{ }^{53} \mathrm{Mn}$ ratio in four samples of Keyes chondrite is $0 \cdot 13$ \pm 0.01 . We use the ${ }^{26} \mathrm{Al},{ }^{53} \mathrm{Mn},{ }^{21} \mathrm{Ne}$ and ${ }^{22 / 21} \mathrm{Ne}$ data in Dhajala samples obtained in our laboratory (Bhandari et al 1978; Gopalan et al 1977; Potdar 1981; Bagolia et al 1978). The ${ }^{26} \mathrm{Al} /{ }^{53} \mathrm{Mn}$ ratio in one sample measured is $0 \cdot 16$. In case of Keyes and St. Severin, the best fit curves drawn through the depth profiles summarised earlier (Bhandari 1984) have been used and two data sets, one corresponding to the near surface sample and other near the deepest point analysed are listed in table 1 . In other cases we have used data reported by Müller et al (1981) and Englert and Herr (1978) as summarised by Moniot $e t$ al (1983). Shielding depths and approximate preatmospheric

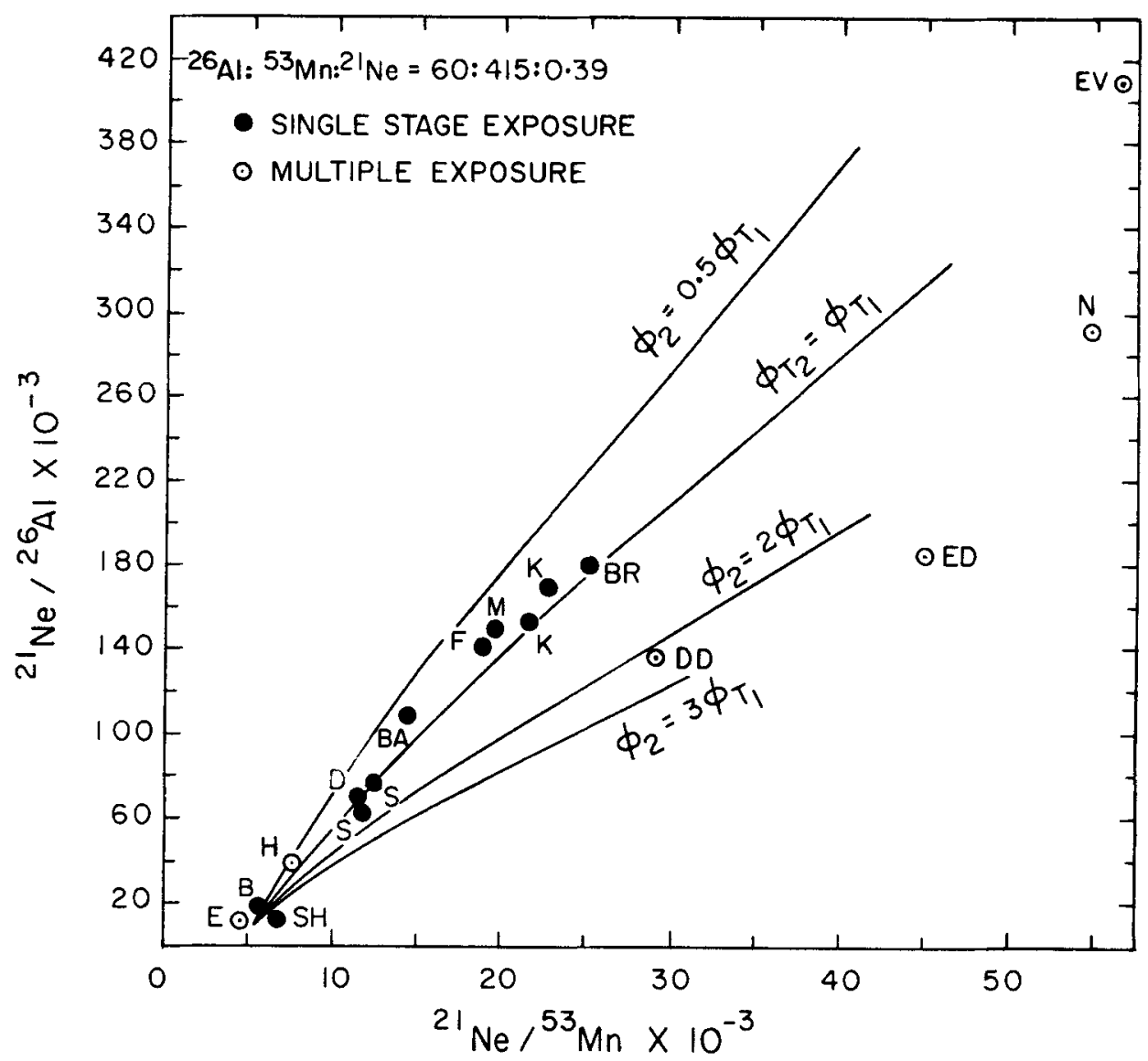

Figure 2. ${ }^{26} \mathrm{Al} /{ }^{21} \mathrm{Ne}$ vs ${ }^{53} \mathrm{Mn} /{ }^{21} \mathrm{Ne}$ correlation diagram for production ratios discussed in the text are plotted for various assumed changes in cosmic ray flux. $\phi_{T_{2}}=\phi_{T_{1}}$ represents the correlation curve for constant cosmic ray flux. If the cosmic ray flux has increased during the past 2 million years, the correlation curve will be below and if the flux has decreased, it will lie above the $\phi_{T_{2}}=\phi_{T_{1}}$ curve. B: Barwell, BA: Bansur, BR: Bruderheim, D: Dhajala, E: Etter, EV: Eva, ED: Edmonson, F: Finney, K: Keyes, M: Madhipura, N: Nogata, S: St. Severin, SH: Shaw, DD: Dalgety Downs, H: Harrisonville. 
sizes, where possible, were calculated using the procedure given in Bhandari et al (1980a) All meteorites with long exposure ages ( $>3$ million years) have been included in table 1 and figure 2. The data on short exposure age meteorites cluster close to the line of constant cosmic ray flux as shown in figure 2 and hence do not indicate any variation in flux. Therefore, only a few typical cases are included.

\section{Discussion}

We will discuss these data in terms of variation of cosmic ray intensity. However, it may be useful to determine the changes expected in isotope production rates in meteorites for constant and variable fluxes first.

\subsection{Isotope production in meteorites}

The isotope production rate $P_{i}$ in a meteorite depends on target element abundance $\left(N_{j}\right)$, excitation function $\left(\sigma_{i j}\right)$ and flux $\phi(E)$ of the primary and secondary nuclear-active particles above the threshold energy $E_{t}$. Since $\phi(E)$ depends on the development of nuclear cascade, it changes with the size of the meteorite $\left(R_{E}\right.$, effective radius, if a spheroidal approximation is made) and shielding depth of the sample $(X)$. Further, if the primary cosmic ray flux has been varying with time, time variation of $\phi(E)$ will lead to time variation in $P_{i}$. The average production over a time $t$ is then given by

$$
P_{i}=\left[\sum_{j} \int_{t} \int_{E_{t}} N_{j} \cdot \sigma_{i j}(E) \cdot \phi\left(E, R_{E}, X, t\right) \mathrm{d} E \mathrm{~d} t\right] /\left[\int_{0}^{t} \mathrm{~d} t\right]
$$

In case of stable isotopes, e.g. ${ }^{21} \mathrm{Ne}$, the observed concentration, $S_{i}$, is given by

$$
S_{i}=P_{i} \cdot t,
$$

provided that no diffusive losses have occurred from the meteorite. On the other hand, in case of radioactive isotopes, e.g. ${ }^{26} \mathrm{Al}$ or ${ }^{53} \mathrm{Mn}$, the observed activity, $A_{k}$, grows with time,

$$
A_{k}=P_{k}\left[1-e^{-t / T_{k}}\right],
$$

where $T_{k}$ is the mean life of the radioisotope. When $t \gg T_{k}$, i.e. at secular equilibrium $A_{k}$ $=P_{k}$ and the exposure age of the meteorite can be calculated by measuring $S_{i}$ and $A_{k}$ if the production ratio $P_{i} / P_{k}$ is independently known.

$$
t=S_{i} /\left[A_{k}\left[1-e^{-t / T}\right]^{-1} \times\left(P_{i} / P_{k}\right)\right]
$$

In chondrites $\boldsymbol{P}_{i}$ and $\boldsymbol{P}_{k}$ change significantly (by upto a factor of 2) from sample to sample because of different shielding depths within a meteorite and its size. However, the ratio $P_{i} / P_{k}$ is nearly the same (within $\pm 20 \%$ ), if nuclides produced in similar reactions (or with similar nucleon energy) are considered. The exposure ages calculated from any isotope pair e.g. ${ }^{21} \mathrm{Ne} /{ }^{26} \mathrm{Al}$ or ${ }^{21} \mathrm{Ne} /{ }^{53} \mathrm{Mn}$ using (4) should therefore be identical for a given cosmic ray flux.

To determine $P_{i} / P_{k}$ we consider three meteorites, St. Severin (LL), Keyes (L) and Dhajala $(\mathrm{H})$, in which ${ }^{53} \mathrm{Mn},{ }^{26} \mathrm{Al},{ }^{21} \mathrm{Ne},{ }^{22} \mathrm{Ne} /{ }^{21} \mathrm{Ne}$ and tracks have been measured (Schultz and Signer 1976; Wright et al 1973; Englert and Herr 1980; Cressy 1975; Lal et 
al 1969; Bhandari et al 1978; Bhattacharya et al 1980; Potdar 1981). These data form a complete set from which depth profiles have been constructed. The shielding depth in space for each sample was calculated from the track density values using the calculated production rates of Bhattacharya et al (1973). These profiles show that the relative production rates of ${ }^{26} \mathrm{Al},{ }^{53} \mathrm{Mn},{ }^{21} \mathrm{Ne}$ at any depth are nearly constant. The production rates of ${ }^{26} \mathrm{Al}:{ }^{53} \mathrm{Mn}:{ }^{21} \mathrm{Ne}$ are 60 atoms/min kg meteorite: 406 atoms/min kg Fe: 0.41 $\times 10^{-8} \mathrm{ccSTP} / \mathrm{g}$ meteorite. M.Y. and their ratios are not very sensitive to depth or size of the chondrite. These rates are also similar to the model calculations of Bhandari (1981) which give production ratios of 60:415:0.39 (expressed in the units mentioned above) whereas the data of Englert and Herr (1978) in saturated meteorites yield values of $60: 392: 0.32$. Using an altogether different set of experimental data Nishiizumi et al (1980) gave the production rates ${ }^{26} \mathrm{Al}:{ }^{21} \mathrm{Ne}$ as 56 atoms/min $\mathrm{kg}$ meteorite (for $\mathrm{H}$ ) or 60 atoms/min kg meteorite (for $\mathrm{L}$ and $\mathrm{LL}): 0.507 \pm 0.039\left(10^{-8} \mathrm{cc}\right.$ STP/g M.Y.) and ${ }^{53} \mathrm{Mn}:{ }^{21} \mathrm{Ne}$ production rate as 414 atoms $/ \mathrm{min} \mathrm{kg} \mathrm{Fe:} 0.302 \pm 0.013$ $\left(10^{-8} \mathrm{cCSTP} / \mathrm{M} . Y\right.$.). Moniot $e$ et al (1983) also favour a low production rate of ${ }^{21} \mathrm{Ne}$ of $0.28 \pm 0.02 \mathrm{cc} \mathrm{STP} / \mathrm{g} \mathrm{M}$.Y. based on ${ }^{10} \mathrm{Be}$ data. Thus there is considerable uncertainty in the production rate of ${ }^{21} \mathrm{Ne}$. Here we adopt the production ratios in the proportion 60:415:0.39 given by Bhandari (1981) which depend slightly on target composition, shape and size of the meteoroid and shielding depth, though these effects are negligible, $<20 \%$ if we confine to ordinary chondrites. In case the cosmic ray flux changes without a significant change in the shape of the energy spectrum, the production ratio is given by

$$
P_{i} / P_{k}=R_{i k} \Phi_{i} / \phi_{k},
$$

where $\boldsymbol{R}_{i k}$ is the production ratio of the isotope for some arbitrary flux and $\bar{\phi}$ represents average flux for the period over which the isotope production is effective.

$$
\text { Therefore } t=S_{i} /\left[A_{k}\left\{1-e^{-t / T_{k}}\right\}^{-1} \cdot R_{i k} \cdot\left(\bar{\phi}_{i} / \bar{\phi}_{k}\right)\right]
$$

We consider here two values of the exposure age $t$, calculated from ${ }^{21} \mathrm{Ne} /{ }^{26} \mathrm{Al}$ and ${ }^{21} \mathrm{Ne} /{ }^{53} \mathrm{Mn}$. In case the average cosmic ray flux has been the same over the mean life of ${ }^{26} \mathrm{Al}$ and ${ }^{53} \mathrm{Mn}$, the two values of $t$ should be the same and they should correlate as shown by the curve $\phi_{T_{1}}=\phi_{T_{2}}$ in figure 2. This figure also shows the correlation of $t$ for some arbitrary change in flux in the past over periods (in million years) indicated by the suffix to $\phi$. If the flux $\left(\phi_{2}\right)$ increases by a factor of two over the past two million years, compared to the flux ( $\phi_{T_{1}}$ ) before, i.e. $\phi_{2}=2 \phi_{T_{1}}$, the exposure age correlation curve lies below the $\phi_{T_{1}}=\phi_{T_{2}}$ line whereas if the flux reduces to half, i.e. $\phi_{2}=0.5 \phi_{T_{1}}$, the curve lies above the $\phi_{T_{1}}=\phi_{T_{2}}$ line. The curves are significantly different for a factor of 2 or 3 variation in flux over 1 or 2 M.Y. period as shown in this figure so that such variations can be easily detected by comparing experimental data with these curves.

\subsection{Complex exposure history of meteorites}

It is assumed in the foregoing discussion that the meteorites are exposed to cosmic rays during their entire exposure period in a fixed geometry i.e. $X$ and $R_{E}$ do not alter with time. As far as the isotope production is concerned, change of $X$ or $R_{E}$ is equivalent to change of effective nucleon flux. Inherent in the mechanism by which meteorites are produced, such as in collisions of different bodies of the solar system (asteroids, for example), it is quite likely that the object is first irradiated to cosmic rays 
buried in the asteroidal regolith (stage $T_{1}$ ) and then exposed as an independent body in space as a meteoroid (stage $T_{2}$ ). In such a case the nucleon flux experienced by the body in stage $T_{1}$ would be less than that in stage $T_{2}$. Analysis of the rare gas data has revealed that about $28 \%$ of meteorites show comparable exposure in stage $T_{1}$ and $T_{2}$ (Bhandari 1981). Therefore, in order to deduce information on cosmic ray variations from meteorite data, meteorites with complex exposure history must be excluded.

To distinguish the cases of multiple exposure and genuine cosmic ray variation we use the criterion suggested earlier by Bhandari and Potdar (1982). The tracks have a steep source function with path length of a few millimeters near the surface, increasing with shielding depth to a few centimeters at large depths (Bhattacharya et al 1973). The track production is therefore small in stage $T_{1}$ and their records in meteorites are mainly due to irradiation in stage $T_{2}$. On the other hand, the spallogenic isotope production increases with depth, initially as a consequence of production of secondary nucleons, and then decreases with a path length of about $50 \mathrm{~cm}$ in chondrites (Arnold 1961; Bhandari and Potdar 1981; Reedy and Arnold 1972). The isotope production, for example of ${ }^{21} \mathrm{Ne}$, therefore would be considerable in both the stages $T_{1}$ and $T_{2}$. Furthermore in case of spallation neon isotope ratio ${ }^{22} \mathrm{Ne} /{ }^{21} \mathrm{Ne}$, it has been found that the ratio is sensitive to shielding depth (Bhandari and Potdar 1982; Eberhardt et al 1966; Cressy and Bogard 1976). In H chondrites, the ratio is about 1.24 near the surface

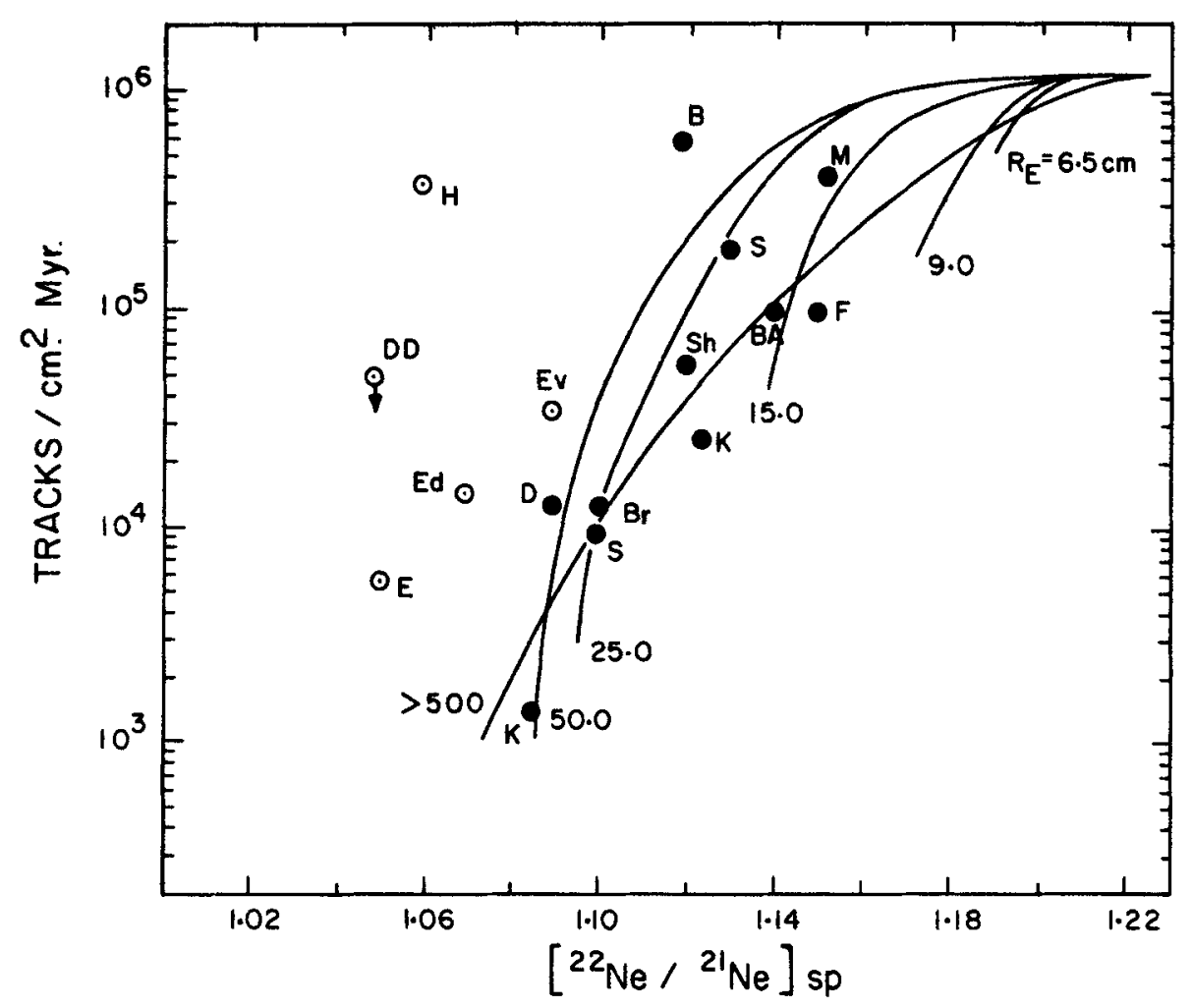

Figure 3. Track production rate vs $\left[{ }^{22} \mathrm{Ne} /{ }^{21} \mathrm{Ne}\right]_{\mathrm{sp}}$ correlation diagram for various effective radii $R_{E}$, following Bhandari and Potdar (1982). The experimental data plotted here are given in table 1 . Symbols are the same as in figure 2 . 
going down to about 1 at a depth of 2 meters. Track production rate vs $\left[{ }^{22} \mathrm{Ne} /{ }^{21} \mathrm{Ne}\right]_{\mathrm{sp}}$ correlation diagram for single-stage exposure has been constructed for meteoroids of various sizes (figure 3). Any departure from the expected correlation for a particular size of the meteoroids can be taken to indicate multiple exposure history (Bhandari and Potdar 1982). We use this criterion in the following analysis to identify meteorites with single and multiple exposures. The track density and $\left[{ }^{22} \mathrm{Ne} /{ }^{21} \mathrm{Ne}\right]_{\mathrm{sp}}$ for all the meteorites are plotted in figure 3. It is clear from this figure that there are six meteorites, namely, Bruderheim, Finney, Dhajala, Keyes, Shaw and St. Severin in which all the data are consistent with single stage exposure. Other meteorites such as Edmonson, Etter, Dalgety Downs and Harrisonville do not satisfy the criteria of single-stage exposure whereas Barwell and Eva are probably consistent with single exposure within the errors of measurement. The first stage exposure, $T_{1}$, in these two cases, if any, has therefore been negligibly small.

\subsection{Analysis of data}

If we consider all the data sets, we find that the points lie on various curves, some on the line of constant flux $\phi_{T_{1}}=\phi_{T_{2}}$ and others like Dalgety Downs, Edmonson and Nogata towards the line representing $\phi_{2}=2 \phi_{T_{1}}$ (figure 2). Clearly if there is a genuine cosmic ray flux variation, all meteorites must show this effect and the data points must lie on the line characteristic of the change of flux. This is not the case. All the well studied meteorites with single-stage exposures e.g. Bruderheim, Dhajala, Keyes and St. Severin lie close to the curve of constant cosmic ray flux $\phi_{T_{1}}=\phi_{T_{2}}$. The meteorites which deviate from this curve are those having complex exposure as indicated by figure 3 . Therefore one can conclude that the apparent departure of data from constant flux line in figure 2 is only due to complex exposure of some of the meteorites and not due to increase in the galactic cosmic ray intensity 2 million years ago. Thus the isotope data in meteorites having simple exposure history do not indicate any variation over the past 1 or 2 million years compared to the intensity over the past $10^{7}$ years.

\section{References}

Arnold J R, Honda M and Lal D 1961 J. Geophys. Res. 663519

Bagolia C, Doshi N, Lal D and Sears D W 1978 Nucl. Track Detection 229

Bhandari N 1981 Proc. Indian Acad. Sci. (Earth Planet. Sci.) 90359

Bhandari N 1984 Lunar and planetary Science (Houston: Lunar Planet Sci. Inst.) vol. 15, p. 50

Bhandari N, Goswami J N, Lal D, MacDougall D and Tamhane A S 1972 Proc. Indian Acad. Sci. A76 27

Bhandari N, Bhattacharya S K and Somayajulu B L K 1978 Earth Planet. Sci. Lett. 40194

Bhandari N and Potdar M B 1982 Earth Planet. Sci. Lett. 58116

Bhandari N, Lal D, Rajan R S, Arnold J R, Marti K and Moore C B 1980a Nucl. Tracks 4213

Bhandari N, Lal D, Nautiyal C M, Padia J T, Potdar M B, Rao M N and Venkatesan T R 1980b Meteoritics 15265

Bhandari N, Potdar M B and Suthar K M 1986 Proc. Indian Acad. Sci. (Earth Planet. Sci). 95

Bhattacharya S K, Goswami J N, Gupta S K and Lal D 1973 Moon 8253

Bhattacharya S K, Imamura M, Sinha N and Bhandari N 1980 Earth Planet. Sci. Lett. 5145

Cressy P J 1975 J. Geophys. Res. 801551

Cressy P J and Bogard D D 1976 Geochim. Cosmochim. Acta 40749

Eberhardt P, Eugster O, Geiss J and Marti K 1966 Z. Naturforsch. 21414 
Englert P and Herr W 1978 Geochim. Cosmochim. Acta 421635

Englert P and Herr W 1980 Meteoritics 15288

Evans J C and Rancitelli L A 1980 in Catalog of antarctic meteorites 1977-78 (eds) U B Marvin and B Mason (Washington: Smithsonian Institution) p. 45

Fleischer R L, Price P B, Walker R M, Maurette M and Morgan G 1967 J. Geophys. Res. 72355

Gopalan K, Rao M N, Suthar K M and Venkatesan T R 1977 Earth Planet Sci Lett 36341

Heimann M, Parekh P P and Herr W 1974 Geochim. Cosmochim. Acta 38217

Herpers U, Herr W and Wölfle R 1968 in Meteorite research (Dordrecht: D Reidel) p. 387

Herpers U and Englert P 1983 J. Geophys. Res. 88 Suppl. B316

Lal D, Lorin J C, Pellas P, Rajan R S and Tamhane A S 1969 in Meteorite research (ed.) P M Millman (Dordrecht: D Reidel) p. 275

Marti K, Shedlovsky J P, Lindstrom R M, Arnold J R and Bhandari N 1969 in Meteorite research (ed.) P M Millman (Dordrecht: D Reidel) p. 246

Moniot R K, Kruse T H, Tuniz C, Savin W, Hall G S, Milazzot T, Pal D and Herzog G H 1983 Geochim. Cosmochim. Acta 471887

Müller O, Hampel W, Kirsten T and Herzog G F 1981 Geochim. Cosmochim. Acta 45447

Nishiizumi K, Regnier S and Marti K 1980 Earth Planet. Sci. Conf. 50156

Potdar M B 1981 Nuclear interactions of the solar and galactic cosmic rays with interplanetary materials Ph.D. thesis, University of Gujarat

Reedy R C and Arnold J R 1972 J. Geophys. Res. 77537

Schultz L and Kruse H 1983 Helium, neon and argon in meteorites: A data compilation (Mainz: Max Planck Institut für Chemie)

Schultz L and Signer P 1976 Earth Planet. Sci. Lett. 30191

Shima M, Murayama S, Okada A, Yabuki H and Takaoka N 1983 Meteoritics 1887

Wright R J, Simms L A, Reynolds M A and Bogard D D 1973 J. Geophys. Res. 781308 